\title{
The Schellong test: detecting orthostatic blood pressure and heart rate changes in German-speaking countries
}

\author{
Alessandra Fanciulli $^{1}\left[\right.$ [ $\cdot$ Nicole Campese $^{2} \cdot$ Gregor K. Wenning $^{1}$ \\ Received: 20 June 2019 / Accepted: 22 June 2019 / Published online: 4 July 2019 \\ c) Springer-Verlag GmbH Germany, part of Springer Nature 2019
}

Keywords Schellong test $\cdot$ Standing test $\cdot$ Orthostatic hypotension $\cdot$ Head-up tilt test $\cdot$ Syncope

\begin{abstract}
"Schellong test" is the eponym used in German-speaking countries to refer to the active standing test for measuring blood pressure and heart rate changes under gravitational stress. The test is named after Fritz Schellong, a European pioneer of cardiovascular autonomic neuroscience.

Schellong, who was born 10 September 1891 in Königsberg (at that time part of Prussia) and died 18 January 1953 in Münster (Germany), became Professor of Internal Medicine in Prague and Münster and a prominent member of the German Society for Circulation Research (Deutsche Gesellschaft für Kreislaufforschung, nowadays known as Deutsche Gesellschaft für Kardiologie-Herz-und Kreislaufforschung, i.e. the German Society for Cardiology, Heart and Circulation Research). Schellong dedicated his scientific career to the understanding of blood pressure regulation, which he summarized in his small monograph Regulationsprïfung des Kreislaufs (Evaluation of the circulatory regulation), published in 1938. In his 133-page book, Schellong described specific tests to evaluate circulatory function with emphasis on blood pressure and heart rate. The monograph included many case examples of these responses, profusely illustrated with 92 graphs (Fig. 1). The original Schellong protocol consisted of three consecutive tests:
\end{abstract}

1. Blood pressure and heart rate measurements in the supine position, at 1-min intervals after standing up, and at 1-min intervals after lying down again

Alessandra Fanciulli

alessandra.fanciulli@i-med.ac.at

1 Department of Neurology, Medical University of Innsbruck, Anichstraße 35, 6020 Innsbruck, Austria

2 Department of Clinical and Experimental Medicine, University of Pisa, Pisa, Italy
2. Blood pressure and heart rate measurements immediately after climbing up a staircase and at 1-min intervals afterwards

3. Measurement of the QRS complex duration on an ECG tracing prior to climbing the stairs in part (2), immediately afterwards, and at 1-min intervals afterwards

Schellong considered the responses in part (1) to depend on neurogenic regulation of peripheral blood vessels, part (2) on both neurogenic control of blood vessels and cardiocirculatory regulation, and part (3) on cardiac regulation only.

After studying the orthostatic blood pressure responses in 92 healthy subjects, he concluded: "As far as the responses in the upright position is concerned, we came to the conclusion that the systolic blood pressure behaves somewhat differently: it can rise a little or remain the same, or sink a little. A decrease of 5 or $10 \mathrm{mmHg}$ is meaningless, but a decrease of $15 \mathrm{~mm}$ is the 'borderline case' ...the diastolic blood pressure usually increases by a few millimetres $(5-10 \mathrm{mmHg})$, sometimes it remains the same, only in a few cases it drops slightly, but increases again while standing. The pulse rate shows an increase of 10-20, even 40 beats per minute. In young people the increase is greater than in older people; in the latter the frequency can also remain the same" [17].

By applying the simple methodology described above, Schellong already understood that orthostatic systolic blood pressure reductions greater than $20 \mathrm{mmHg}$ are abnormal in the clinical setting [10], that diastolic blood pressure probably contributes to a lesser extent to orthostatic blood pressure regulation and its disorders [7], and that, above all, aging significantly affects baroreflex function $[2,13]$.

Nowadays there are much more sophisticated ways to examine both cardiac intrinsic and baroreflex function, but a simplified version of the Schellong, or standing test, i.e. the evaluation of heart rate and blood pressure changes 


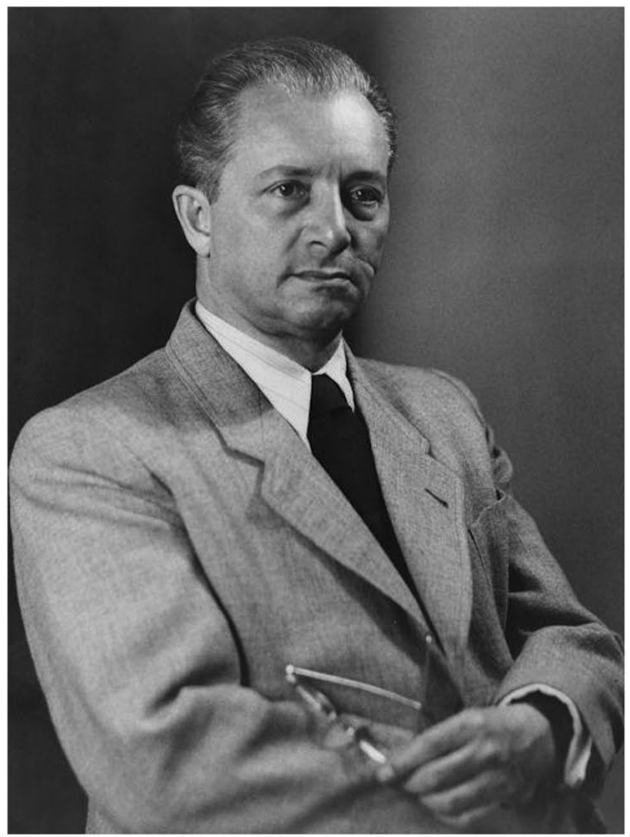

\section{Abb. 64}

C. v. B., $\delta^{\star}, 67$ Jahre. In anstrengendem Beruf jahrzehntelang viel gearbeitet. Seit längerer Zeit allgemeine Schwäche, Schwindelgefühl, Händezittern, Unfähigkeit sich zu konzentrieren, Stimmungsschwankungen, Scheu vor Geselligkeit, Herzdruck und Luftmangel. - Befund: Roter Pykniker. Leichte Skoliose, Herz und Gefäße dem Alter entsprechend.

Regulationsprüfung 22. 8. 1934: Blutdruck in der Ruhe zwischen 145/75 und 132/70, Puls zwischen 70 und 106. I. Allmählicher und starker Abfall des systolischen Blutdruckes, auch der diastolische fällt um $15 \mathrm{~mm}$ ab, große Blutdruckamplitude. Pulsfrequenz wenig erhöht, geht nach Teil I auf 70 Schläge zurück. II. Nur einmal Treppenlaufen in der langen Zeit von 58 Sekunden. Daher kein Pulsanstieg. Kurve des systolischen Druckes in Berūcksichtigung der Laufzeit zu hoch, fällt nur langsam ab. III. QRS zeigt trotz Fehlen des Pulsanstieges gute Verkūrzung. - Beurtei -

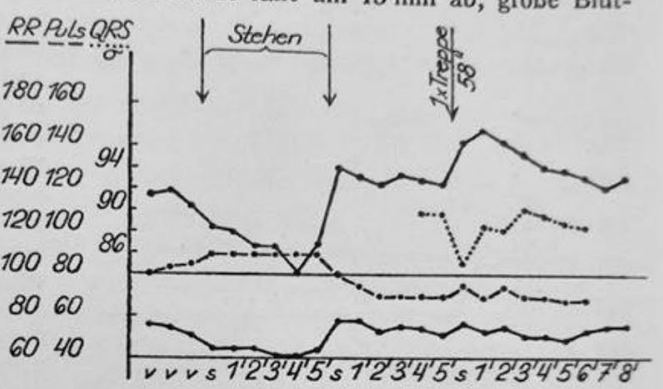

Abb. 64.

lung: Hypodyname (zen-

trale) Regulationsstörung in Teil I. Schwindelgefühl und Schwăche (soweit kreislaufbedingt) dadurch erklärt. Kein Zeichen einer Herzschädigung.

Fig. 1 Left panel: Fritz Schellong in 1950, family archive. Source: Wiki Commons. https://commons.wikimedia.org/wiki/File:Fritz _Schellong_1950.jpg?uselang=de. Right panel: Example of a Schellong test in a patient presumably affected by parkinsonism and neurogenic orthostatic hypotension: "C.v.B., male, 67 years old. Worked for years under stressful conditions. For a long time now, general weakness, dizziness, hand tremor, inability to concentrate, mood fluctuations, reluctance to social life, angina and dyspnea. Findings: red endomorph. Slight scoliosis, normal heart and blood vessels. Regulation test 22.08.1934: Blood pressure at rest between 145/75 and 132/70, pulse between 70 and 106. Part I. Progressive and severe

from the supine to upright position, is still recommended as a bedside screening measure in patients with suspected cardiovascular autonomic dysfunction, including syncope, whenever the patient's clinical condition allows it $[3,18]$.

There is no universal standardized protocol for performing a standing test, although this usually consists of a supine phase of 5-10 min, followed by an active standing phase of at least $3 \mathrm{~min}$, ideally $5-10 \mathrm{~min}$. Blood pressure and heart rate are measured at the end of the supine phase and at 1-min intervals during the orthostatic challenge. If the patient is unable to stand up from the supine position, a sitting-to-standing protocol is acceptable [11], although less sensitive than the supine-to-standing one [4].

For screening purposes and when no other technologies are available, heart rate can be measured manually or with a pulse oximeter, while blood pressure can be obtained with an arm cuff [3].

A sustained blood pressure fall of at least $20 \mathrm{mmHg}$ in systolic or at least $10 \mathrm{mmHg}$ in diastolic or an absolute systolic blood pressure below $90 \mathrm{mmHg}$ after $3 \mathrm{~min}$ standing qualifies for orthostatic hypotension $[3,10]$. decrease of systolic blood pressure, also diastolic blood pressure drops by $15 \mathrm{mmHg}$, large blood pressure amplitude. Pulse frequency slightly increased, afterwards back to 70 beats. Part II. Only one stair case in the long time of $58 \mathrm{~s}$. Therefore no pulse increase. Systolic blood pressure curve too high in consideration of the exercise time, delayed return to baseline. Part III. QRS shows a good shortening despite the lack of pulse increase. Interpretation: hypodynamic (central) regulatory disorder in part I. This explains dizziness and weakness (as far as circulation is their cause). No sign of heart damage." First published in F. Schellong "Regulationsprüfung des Kreislauf", Theodor Steinkopff Verlag (Dresden, Leipzig) 1938; C, 2d: 100-101

Orthostatic hypotension may be symptomatic, i.e., causing symptoms of organ hypoperfusion such as dizziness, cognitive slowness, blurred vision, or shoulder or neck pain; or asymptomatic, mostly depending on the lowest blood pressure value when standing [15]. In the clinical setting, the most frequent causes of orthostatic hypotension are nonneurogenic, i.e., volume depletion (dehydration, blood loss) and medication side effects. In non-neurogenic orthostatic hypotension, baroreflex function is preserved, and the fall in blood pressure is compensated by a marked rise in heart rate. In contrast, when orthostatic hypotension is caused by neurodegenerative, metabolic, autoimmune, or genetic disorders affecting afferent or efferent autonomic pathways, baroreflex dysfunction is evident, and the orthostatic heart rate response to hypotension is reduced or absent [14]. Evaluating the supine-to-standing heart rate changes may thus provide invaluable information about the cause of the orthostatic hypotension, and inform treatment.

Blood pressure measurements in the supine position may also detect supine hypertension [6], defined as blood pressure $\geq 140 / 90 \mathrm{mmHg}$ at the end of a supine phase of at least 5 min in patients with neurogenic orthostatic hypotension. 
Neurogenic supine hypertension affects about $50 \%$ of patients with neurogenic orthostatic hypotension [5] and, if present, has major therapeutic and prognostic implications.

The active standing test may also detect delayed orthostatic hypotension, i.e., occurring beyond $3 \mathrm{~min}$ of orthostatic challenge [3], although prolonging the test to $10 \mathrm{~min}$ or more may be uncomfortable for geriatric patients. In this case a tilt-table test may be preferable.

There is conflicting evidence in the literature as to whether a standing or a head-up tilt test, i.e. an active or passive orthostatic challenge, is more sensitive for detecting orthostatic hypotension $[1,12]$ : these tests are eventually to be considered of complementary value in the diagnostic workup of orthostatic hypotension.

Continuous heart rate and blood pressure monitoring during a standing test may also identify transient orthostatic blood pressure changes, such as initial orthostatic hypotension (i.e. a BP fall $>40 / 20 \mathrm{mmHg}$ within the first $15 \mathrm{~s}$ upon standing, with recovery within $30 \mathrm{~s}$ ) or delayed blood pressure recovery (i.e. a BP fall $>20 / 10 \mathrm{mmHg}$ persisting $30 \mathrm{~s}$ after standing) [9], which have recently been acknowledged as possible causes of falls and syncope in the aging population $[8,16]$.

A standing test may be also used to screen for postural tachycardia syndrome (POTS). In case of suspected vasovagal syncope extended continuous heart rate and blood pressure monitoring for up to $45 \mathrm{~min}$ at 60 -degrees head-up tilt is often necessary, in order to diagnose and classify syncope [3]. The sensitivity is indeed higher during a head-up tilt examination, thanks to the exclusion of the muscular leg pump, to the possibility of prolonging the test beyond 10 min or adding provocations like sublingual nitro-glycerine or isoproterenol [3].

Bernard of Chartres, a twelfth-century philosopher, said that "we, the Moderns, are like dwarves perched on the shoulders of giants, the Ancients, and thus we are able to see more and farther than the latter. And this is not at all because of the acuteness of our sight or the stature of our body, but because we are carried aloft and elevated by the magnitude of the giants." Thanks to advanced technology, modern clinical autonomic medicine is nowadays able to diagnose, quantify, and monitor over time a wide range of cardiovascular autonomic disorders. More than 80 years ago, however, Schellong already understood the key point of cardiovascular autonomic testing: to stress the baroreflex by standing up.

\section{Funding None}

\section{Compliance with ethical standards}

Conflict of interest The authors declare no conflicts of interest.

\section{References}

1. Aydin AE, Soysal P, Isik AT (2017) Which is preferable for orthostatic hypotension diagnosis in older adults: active standing test or head-up tilt table test? Clin Interv Aging 12:207-212

2. Braune S, Auer A, Schulte-Monting J, Schwerbrock S, Lucking $\mathrm{CH}$ (1996) Cardiovascular parameters: sensitivity to detect autonomic dysfunction and influence of age and sex in normal subjects. Clin Auton Res 6:3-15

3. Brignole M, Moya A, de Lange FJ, Deharo JC, Elliott PM, Fanciulli A, Fedorowski A, Furlan R, Kenny RA, Martin A, Probst V, Reed MJ, Rice CP, Sutton R, Ungar A, van Dijk JG, Group ESCSD (2018) 2018 ESC Guidelines for the diagnosis and management of syncope. Eur Heart J 39(21):1883-1948

4. Cooke J, Carew S, O'Connor M, Costelloe A, Sheehy T, Lyons D (2009) Sitting and standing blood pressure measurements are not accurate for the diagnosis of orthostatic hypotension. QJM 102:335-339 (Monthly Journal of the Association of Physicians)

5. Fanciulli A, Gobel G, Ndayisaba JP, Granata R, Duerr S, Strano S, Colosimo C, Poewe W, Pontieri FE, Wenning GK (2016) Supine hypertension in Parkinson's disease and multiple system atrophy. Clinic Auton Res 26:97-105 (Official Journal of the Clinical Autonomic Research Society)

6. Fanciulli A, Jordan J, Biaggioni I, Calandra-Buonaura G, Cheshire WP, Cortelli P, Eschlboeck S, Grassi G, Hilz MJ, Kaufmann H, Lahrmann H, Mancia G, Mayer G, NorcliffeKaufmann L, Pavy-Le Traon A, Raj SR, Robertson D, Rocha I, Struhal W, Thijs R, Tsioufis KP, van Dijk JG, Wenning GK (2018) Consensus statement on the definition of neurogenic supine hypertension in cardiovascular autonomic failure by the American Autonomic Society (AAS) and the European Federation of Autonomic Societies (EFAS): endorsed by the European Academy of Neurology (EAN) and the European Society of Hypertension (ESH). Clin Auton Res 28(4):355-362

7. Fedorowski A, Hamrefors V, Sutton R, van Dijk JG, Freeman R, Lenders JW, Wieling W (2017) Do we need to evaluate diastolic blood pressure in patients with suspected orthostatic hypotension? Clin Auton Res 27:167-173

8. Finucane C, O'Connell MD, Fan CW, Savva GM, Soraghan CJ, Nolan H, Cronin H, Kenny RA (2014) Age-related normative changes in phasic orthostatic blood pressure in a large population study: findings from The Irish Longitudinal Study on Ageing (TILDA). Circulation 130:1780-1789

9. Finucane C, van Wijnen VK, Fan CW, Soraghan C, Byrne L, Westerhof BE, Freeman R, Fedorowski A, Harms MPM, Wieling W, Kenny R (2019) A practical guide to active stand testing and analysis using continuous beat-to-beat non-invasive blood pressure monitoring. Clin Auton Res. https://doi.org/10.1007/ s10286-019-00606-y

10. Freeman R, Wieling W, Axelrod FB, Benditt DG, Benarroch E, Biaggioni I, Cheshire WP, Chelimsky T, Cortelli P, Gibbons CH, Goldstein DS, Hainsworth R, Hilz MJ, Jacob G, Kaufmann H, Jordan J, Lipsitz LA, Levine BD, Low PA, Mathias C, Raj SR, Robertson D, Sandroni P, Schatz I, Schondorff R, Stewart JM, van Dijk JG (2011) Consensus statement on the definition of orthostatic hypotension, neurally mediated syncope and the postural tachycardia syndrome. Clin Auton Res 21:69-72

11. Gibbons $\mathrm{CH}$, Schmidt P, Biaggioni I, Frazier-Mills C, Freeman R, Isaacson S, Karabin B, Kuritzky L, Lew M, Low P, Mehdirad A, Raj SR, Vernino S, Kaufmann H (2017) The recommendations of a consensus panel for the screening, diagnosis, and treatment of neurogenic orthostatic hypotension and associated supine hypertension. J Neurol 264(8):1567-1582 
12. Jamnadas-Khoda J, Koshy S, Mathias CJ, Muthane UB, Ragothaman M, Dodaballapur SK (2009) Are current recommendations to diagnose orthostatic hypotension in Parkinson's disease satisfactory? Mov Disord 24:1747-1751 (Official journal of the Movement Disorder Society)

13. Ndayisaba JP, Fanciulli A, Granata R, Duerr S, Hintringer F, Goebel G, Krismer F, Wenning GK (2015) Sex and age effects on cardiovascular autonomic function in healthy adults. Clin Auton Res 25:317-326

14. Norcliffe-Kaufmann L, Kaufmann H, Palma JA, Shibao CA, Biaggioni I, Peltier AC, Singer W, Low PA, Goldstein DS, Gibbons CH, Freeman R, Robertson D, Autonomic Disorders C (2018) Orthostatic heart rate changes in patients with autonomic failure caused by neurodegenerative synucleinopathies. Ann Neurol 83:522-531

15. Palma JA, Gomez-Esteban JC, Norcliffe-Kaufmann L, Martinez J, Tijero B, Berganzo K, Kaufmann H (2015) Orthostatic hypotension in Parkinson disease: how much you fall or how low you go? Mov Disord 30:639-645 (Official journal of the Movement Disorder Society)

16. Romero-Ortuno R, Cogan L, Foran T, Kenny RA, Fan CW (2011) Continuous noninvasive orthostatic blood pressure measurements and their relationship with orthostatic intolerance, falls, and frailty in older people. J Am Geriatr Soc 59:655-665

17. Schellong F (1938) Regulationsprüfung des Kreislaufs. Theodor Steinkopff, Dresden und Leipzig

18. Writing Committee M, Shen WK, Sheldon RS, Benditt DG, Cohen MI, Forman DE, Goldberger ZD, Grubb BP, Hamdan MH, Krahn AD, Link MS, Olshansky B, Raj SR, Sandhu RK, Sorajja D, Sun BC, Yancy CW (2017) 2017 ACC/AHA/HRS guideline for the evaluation and management of patients with syncope: a report of the American College of Cardiology/American Heart Association Task Force on Clinical Practice Guidelines and the Heart Rhythm Society. Heart Rhythm 14:e155-e217 